No. 8

Money, Neutrality of Consumption Taxes,

and Growth

in Intertemporal Optimizing Models

Jun-ichi Itaya

Revised November 1993

Department of Economics

Otaru University of Commerce 


\title{
Money, Neutrality of Consumption Taxes, and Growth in Intertemporal Optimizing Models"
}

Revised November 1993

\author{
Jun-ichi Itaya \\ Associate Professor of Economics \\ Department of Economics \\ Otaru University of Commerce
}

Address for Correspondence:

Department of Economics

Otaru University of Commerce

3-5-21 Midori, Otaru

Hokkaido 047, JAPAN

* I wish to thank Yoshinori Kon and Hiroaki Hayakawa for valuable comments and suggestions. Any errors are mine. This research was supported in part by a grant from the Yamada Foundation of Promotion of Research. Any comments are welcomed. 


\begin{abstract}
This paper considers the effects of a proportional consumption tax with the same rate over time on the real growth path of a monetary economy. The analysis uses a variety of stylized monetary growth models in which individual's consumption-saving decision is based on intertemporal utility maximization, such as the money-in-utility, transaction-costs, and cash-in-advance models. The first key result is that the neutrality of the consumption tax may or may not be true, depending on the nature or the role of money in the respective models. The second is that the consumption tax is generally superior to the inflation tax (i.e., the monetary growth rate) in terms of steady state welfare when raising a given amount of revenue.
\end{abstract}




\section{Introduction}

A number of prominent economists, e.g., Fisher(1939), Kaldor(1955), Summers(1981), have proposed a consumption tax (for instance, an expenditure tax, general sales tax, or VAT) as an alternative to the existing tax system on the grounds that a change in a proportional consumption tax with the same rate over time would not directly distort intertemporal consumption-savings behavior. Indeed, it is a widely accepted view that a reform towards the consumption tax would promote capital accumulation and thus improve social welfare.

Recently this conventional wisdom has been rigorously investigated by a number of authors using two types of dynamic general equilibrium models with solid microeconomic foundations: the life-cycle growth model with overlapping generations [Summers(1981), Menchik and David(1982), Seidman(1983), Batina(1987)] and the infinitely-lived representative agent (or the single dynastic family) model [Schenone(1975), Sinn(1982, 1987), Abel and Blanchard(1983), and Itaya (1991)].

In the former, Summers showed that a change in the proportional consumption tax with the same rate over time does not affect savings because of fixed labor supply and homothetic utility, despite tax revenue is not rebated to consumers. In contrast, Seidman showed that incorporating a bequest motive into Summer's model undermines such neutrality. Menchik and David pointed out that the consumption tax is neutral in the sense that the marginal rate of substitution between consumption and bequests is not distorted if bequests as well as lifetime consumption are levied at the same rate. Batina extended the Becker-Barro altruistic model to contain both cash bequests and human capital investments and to allow for endogenous fertility decisions, and concluded that neutrality almost always fails in spite of fixed labor supply. 
In contrast, the latter authors have reached more clear-cut conclusions; namely, abstracting from labor-leisure choice, such a consumption tax does not affect the capital stock either along the growth path or in the steady-state as long as tax revenue is fully rebated to consumers. Furthermore, if an increase in the consumption tax is accompanied by a corresponding decrease in other distortionary taxes (e.g.,profits or wage taxes) that generally hurt capital formation, it would augment savings, foster economic growth, and thus improve social welfare.

However, these analyses have been all carried out within the framework of a non-monetary model in which money neither plays any essential role in economic activity nor yields intrinsic utility. Such a restrictive structure limits the validity of their results, not only because it may be misleading as a description of actual economies where everyone would hold money for a variety of reasons, but also because if savings take place in the form of money in addition to real assets (i.e.capital), alternative rates of the consumption tax may distort the consumption-savings decisions through the portfolio adjustment effect, thereby potentially invalidating neutrality. Therefore, the main purpose of the present paper is to reexamine the neutrality of the consumption tax in dynamic general equilibrium models of monetary growth where a representative consumer undertakes intertemporal optimizing behavior. We shall carry out the analysis using three recently developed models which highlight different hypotheses of the roles of money: the money-in-theutility-function (MUF) model, the transaction-costs (TC) model, and the cash-in-advance (CIA) model. In order to separate the effects on consumption-savings behavior from those caused by the distortion associated with leisure-labor choice, I retain the assumption of 
inelastic labor supply, except for the shopping-time model in which the supply of labor and the demand for money are determined jointly by the time constraint. Even though inelastic labor supply is assumed, I shall show that the neutrality of the consumption tax may or may not hold true, depending on the role or the nature of money in the assumed model.

Moreover, I study the welfare implications of the consumption tax and monetary policy on efficiency grounds. Inflation as caused by expansionary monetary policy may also be regarded as a tax on real balances (i.e., an inflation $t a x$ ) in the sense that a rise in nominal prices reduces the real value of money for purchases. It is also well known that the welfare costs of inflation are relatively smaller compared with those of other distortionary taxes. Despite these similarities, most of the public finance literature have focused on the efficiency of labor and capital income taxes, while the monetary growth literature has exclusively discussed the effects of monetary growth on macroeconomic aggregates or welfare costs. Thus, this paper attempts to bridge this gap by considering them together as a resource of revenue. It will be shown that the consumption tax is generally superior to the inflation one in terms of steady state welfare.

Section 2 analyzes the effects of the consumption tax on macroeconomic aggregates and steady state welfare in the MUF model. Section 3 and 4 perform the same task in the TC (i.e., the shoppingcosts, the money-in-the-production-function, and the shopping-time) model and the CIA model, respectively. Section 5 summarizes three main conclusions by comparing the results obtained in these models, and discusses briefly the extension of the respective models to involve endogenous labor supply. 


\section{The Money-In-The-Utility-Function Model}

Following Sidrauski (1967), let a representative infinitely-lived consumer with perfect foresight determine its optimal paths of consumption, capital accumulation, and real money balances by solving the following intertemporal optimization problem:

$$
\max \int_{0}^{\infty} u(c(t), m(t)) e^{-\delta t} d t,
$$

subject to

$$
\begin{aligned}
& a(t)=k(t)+m(t), \\
& \dot{a}(t)=f(k(t))+x(t)-\tau c(t)-n a(t)-\pi(t) m(t), \\
& a(0)=k_{0}+m_{0}>0,
\end{aligned}
$$

where $u(c, m)$ is a time-invariant instantaneous utility function, monotone increasing in (per capita) consumption at time $t, c(t)$, and (per capita) real money balances at time $t, m(t)$, strictly concave, and twice continuously differentiable; $x(t)$ is (per capita) lump-sum transfer from the government equal to $\theta m(t)+(\tau-1) c(t)^{2} ; k(t)$ is the stock of (per capita) capital at time $t ; a(t)$ is the stock of (per capita) non-human wealth allocated between capital and real balances; $\pi(t)$ is the inflation rate at time $t ; f(k)$ is the (per capita) constant-returns-to-scale neoclassical production function satisfying the Inada conditions; $\delta, \theta$, $\tau$, and $n$ are (positive) constant rates of time preference, monetary expansion, proportional consumption taxes, and population growth, respectively. I assume that both consumption and real balances are normal goods and that there is neither depreciation nor technical change.

Straightforward application of Pontryagin's Maximum Principle leads to the following necessary conditions for an interior optimal path ${ }^{4}$ : 


$$
\begin{aligned}
& {\left[\frac{{ }^{c u}{ }_{c c}}{u_{c}}\right] \frac{\dot{c}}{c}=(n+\delta)-f^{\prime}(k)-\left[\frac{{ }^{m u}{ }_{c m}}{u_{c}}\right] \frac{\dot{m}}{m},} \\
& \frac{\dot{m}}{m}=\theta+f^{\prime}(k)-n-\frac{\tau u_{m}}{u_{c}}, \\
& \dot{k}=f(k)-n k-c, \\
& \lim _{t \rightarrow \infty} u_{c}(c(t), m(t)) a(t) \exp (-\delta t)=0,
\end{aligned}
$$

where $u_{i}\left(u_{i j}\right)$ denotes the first-order (second-order) partial derivative of $u$ w.r.t. argument $i$ ( $i$ and $j$ ). It may be noted that if real balances do not have any utility (i.e., $u_{m}=0$ ), which corresponds to a non-monetary economy, then the consumption tax rate drops out of this system, so that a permanent change in $\tau$ leaves all real variables unchanged along the transition as well as in the steady state paths.

In the steady-state, setting $\dot{c}=0, \dot{k}=0$, and $\dot{m}=0$ gives:

$$
\begin{aligned}
& f^{\prime}\left(k^{*}\right)=n+\delta, \\
& u_{m}\left(c^{*}, m^{*}\right) / u_{c}\left(c^{*}, m^{*}\right)=(\theta+\delta) / \tau, \\
& f\left(k^{*}\right)=c^{*}+n k^{*},
\end{aligned}
$$

where the starred variables pertain to the steady state values. Eq. (4a) determines solely the steady state capital intensity, because the fixed discount rate of the representative agent is unaffected by a change in $\tau$. Having determined $k^{*}$, the steady state level of consumption is given by (4c). Thus they are both independent of $\tau$; namely, the consumption tax is neutral in terms of these steady state real variables. Finally, (4b) means that the marginal rate of substitution (henceforth MRS) between consumption and money equals the nominal interest rate divided by the consumption tax rate (i.e., the opportunity cost of holding money in terms 
of consumption foregone). Given $k^{*}$ and $c^{*}$, differentiating (4b) w.r.t. $\tau$ yields

$$
\frac{d m^{*}}{d \tau}=\frac{u_{m}{ }^{u}{ }_{c}}{\tau\left(u_{m}{ }^{u} m^{\left.-u_{c}{ }^{u}{ }\right)}\right)}>0 .
$$

That is, an increase in $\tau$ means a rise in the effective price of consumption goods (or a reduction in the opportunity cost of money) at every instant in time, thus raising the steady state demand for money.

This steady state neutrality result and its reason coincide with Sidrauski's superneutrality result of money. Thus the basic reason for neutrality is the fixity of the steady state discount rate, which is unaffected by variations in real money balances. Once the modified golden rule condition (4a), therefore, is allowed to depend directly on real balances, neutrality fails to hold. It should be also noted that the effect of an increase in $\tau$ on real balances is opposite to that of a higher money growth rate, reflecting their opposing effects on the opportunity cost of holding money. As shown in Table 1, this feature is more manifest in the model of recursive preference with money in the utility function, in which the effects of these two taxes on all macroeconomic aggregates are opposite. This further indicates that the consumption tax is Pareto superior to the inflation one in terms of steady state welfare when raising a given amount of revenue, because utility is an increasing function of consumption and money. Instead of the elimination of the inflation tax (called Friedman's optimal quantity of money rule), therefore, increasing the consumption tax leads to a Pareto improvement in steady state welfare as well.

Next, to see whether or not a change in the consumption tax affects the transitional dynamic path of this model, we obtain the following linear approximation of $(3 a),(3 b)$ and $(3 c)$ around the steady state: 


$$
\left[\begin{array}{l}
\dot{c} \\
\dot{m} \\
\dot{k}
\end{array}\right]=\left[\begin{array}{ccc}
\tau \frac{m^{*}}{u_{C c} J_{1} u_{c m}} & \tau \frac{m^{*}}{u_{c c} J_{2} u_{c m}} & -\frac{f^{\prime \prime}}{u_{c c}\left(u_{c}+m^{*} u_{c m}\right)} \\
-\tau m^{*} J_{1} & -\tau m^{*} J_{2} & m^{*} f^{\prime \prime} \\
-1 & 0 & \delta
\end{array}\right]\left[\begin{array}{c}
c-c^{*} \\
m-m^{*} \\
k-k^{*}
\end{array}\right]
$$

where $J_{1} \equiv\left(u_{c m} u_{c}-u_{m} u_{c c}\right) /\left(u_{c}\right)^{2}>0$ and $J_{2} \equiv\left(u_{m m} u_{c}-u_{m} u_{c m}\right) /\left(u_{c}\right)^{2}<0$.

Under the constant relative risk averse (CRRA) utility function ${ }^{6}$ :

$$
u(c, m)=\frac{\left(c^{\alpha} m^{\beta}\right)^{1-\gamma}}{1-\gamma}, \quad \gamma>0, \quad \alpha+\beta \leq 1,
$$

the characteristic equation of the system (5) is given by:

$$
\begin{aligned}
\psi_{r}(\lambda, \tau)= & -\lambda^{3}+\lambda^{2}\left[\delta+(\theta+\delta) \frac{1-(\alpha+\beta)(1-\gamma)}{1-\alpha(1-\gamma)}\right]-\lambda\left[\delta(\theta+\delta) \frac{1-(\alpha+\beta)(1-\gamma)}{1-\alpha(1-\gamma)}\right. \\
& \left.+f^{\prime \prime} c^{*} \frac{1+\beta(1-\gamma)}{1-\alpha(1-\gamma)}\right]+\frac{f^{\prime \prime} c^{*}(\theta+\delta)}{1-\alpha(1-\gamma)}=0 .
\end{aligned}
$$

Since neither the consumption tax rate $\tau$ nor real balances appears in (7), its unique negative root $\lambda$ is invariant to alternative rates of $\tau$. Consequently, the paths of capital accumulation and of consumption remain unchanged, while that of real balances is affected although the effect is ambiguous? A permanent increase in $\tau$ reduces the opportunity cost of money, thereby stimulating the demand for money at all times. However, owing to both the constant intertemporal elasticity of overall consumption $\left(c^{\alpha} m^{\beta}\right)$ and the homogeneity of consumption and money, the own elasticity of the marginal utility of consumption $\left(c_{c c} / u_{c}\right)$ and the cross elasticity of the marginal utility of money $\left(m u_{C m} / u_{c}\right)$ are constant, and the linearized coefficient of $\left(\tau u_{m} / u_{c}\right)$, evaluated at the steady state, is independent of $m$ as well as $\tau$, so that the growth path of consumption is unaffected by changing $\tau$. This contrasts sharply with the case of monetary policy where, even under the same preference except for $\gamma=1$, changing the inflation tax affects the transition paths of consumption, 
through variations in $\dot{m} / m$, and thus that of capital accumulation [Fischer (1979)].

However, such neutrality is not robust to other utility functions. For example, with the constant absolute risk aversion utility function, it follows not only that such neutrality fails to hold, but also that capital formation is adversely affected, as shown in Appendix A. The reason is that increasing $\tau$ affects negatively both elasticities appearing in (3a) due to increased real balances, thereby lowering the growth rate of consumption. By contrast, if preferences are separable in consumption and real balances (i.e., $u_{c m}=0$ ), neutrality would return, for (3a) depends only on $\mathrm{cu}_{c c} / u_{c}$ that is uninfluenced by the level of real balances. Nevertheless, we may conclude that the consumption tax rate would affect the transition paths of those real variables on the grounds that, with the non-separable utility function, $c u_{c c} / u_{c}$ and $m u_{c m} / u_{c}$ are generally functions of real balances.

\section{The Transaction-Costs Model}

Money would provide 'shopping services' in the form of reducing transaction costs or freeing resources (real commodities or time) from transaction activities for either personal consumption or production. Assume first that transaction costs reduce the effective level of personal consumption, which may be referred to as a shopping-costs model.

Thus, a representative consumer maximizes

$$
\int_{0}^{\infty} u(c) e^{-\delta t} d t
$$

subject to $(2 a),(2 c)$, and

$$
\dot{a}=f(k)+x-\tau c-v(c, m)-n a-\pi m,
$$

which replaces $(2 b)^{8}$. The transaction costs function $v(c, m)$ stands for the 
fraction of real resources that are necessary for facilitating transactions. We assume that $v_{c}>0, v_{c c} \geq 0, v_{m}<0, v_{m m}>0, v_{c m}<0, \lim _{m \rightarrow 0} v_{m}=-\infty$, $v(0, m)=0$, and $\lim _{m \rightarrow m} v=\lim _{m \rightarrow m} v_{c}=\lim _{m \rightarrow m} v_{m}=0$ where $m^{*}$ is the satiation level of money.

In a similar fashion as in the previous section, we obtain the following equations characterizing an optimal path:

$$
\begin{aligned}
& {\left[1+\sigma(c) \frac{c v_{c c}}{\tau+v_{c}}\right] \frac{\dot{c}}{c}=\sigma(c)\left[f^{\prime}(k)-(n+\delta)\right]-\sigma(c) \frac{m v_{c m}}{\tau+v_{c}} \frac{\dot{m}}{m}} \\
& \frac{\dot{m}}{m}=\theta+f^{\prime}(k)-n+v_{m}(c, m), \\
& \dot{k}=f(k)-c-v(c, m)-n k,
\end{aligned}
$$

where $\sigma(c)$ is the intertemporal substitution elasticity.

In the steady state, we have (4a),

$$
\begin{aligned}
& -v_{m}\left(c^{*}, m^{*}\right)=\theta+f^{\prime}\left(k^{*}\right)-n, \\
& f\left(k^{*}\right)=c^{*}+v\left(c^{*}, m^{*}\right)+n k^{*} .
\end{aligned}
$$

Eq. (10a) means the equality between the marginal benefit of economizing on transaction costs and the opportunity cost of holding money in the steady state. A change in $\tau$ affects neither the capital stock, consumption nor real balances in the steady state, because the consumption tax does not appear in these steady state conditions. This neutrality is stronger than the superneutrality of money in the sense that a change in $\theta$ does not affect $k^{*}$ but does $c^{*}$ and $m^{*}$. Although these effects are generally ambiguous, we obtain

$$
\frac{d c^{*}}{d \theta}=\frac{v_{m}}{\Gamma_{V}}<0 ; \quad \frac{d m^{*}}{d \theta}=-\frac{1+V_{c}}{\Gamma_{V}}<0
$$

provided $\Gamma_{V} \equiv-v_{m c} v_{m}+v_{m m}\left(1+v_{c}\right)>010$. The resulting negative effect on consumption reflects the waste from increased transaction costs due to 
decreased real balances. A comparison of (11) and the above neutrality result reveals that under the assumption of stable saddlepoint the consumption tax is superior to the inflation tax in terms of steady state welfare because utility is an increasing function of consumption.

Since (9a) involves the second derivatives of the utility and transaction costs functions, making comparative dynamics exercises relies on still-higher derivatives, ${ }^{1}$ I assume both the CRRA utility function and $v(c, m)=c v(m)$. Appendix B shows that with this formulation an increase in $\tau$ leads to a fall in the speed of capital accumulation for $k(t)<k^{*}$, while the transitional responses of consumption and money are ambiguous. The no-arbitrage condition between money and capital, $-v_{m}=f^{\prime}(k)+\pi$, is unaffected by alternative rates of $\tau$, so that the portfolio of savings remains unchanged, whereas the effective price of the consumption good at every instant in time, $\tau+v(m(t))$, and thus the MRS between consumption at two points is distorted by changing $\tau$. More precisely, suppose that the level of real balances is monotonically increasing over time, that effective price monotonically declines. Hence, a permanent and uniform increase in $\tau$ raises the future effective prices by a greater percentage than the initial one, thus deriving up intertemporal relative prices. Consequently, initial consumption goes up, and thus the speed of capital accumulation as well as savings fall.

Alternatively, Drazen(1979) and McCallum(1983) have provided the so-called shopping-time model in which a consumer must spend time in transacting (i.e., shopping), instead of real commodities. Hence, he must allocate (fixed) $H$ units of time among leisure $z$, labor $l$, and time spent on transactions $s(m)$ at each instant ${ }^{12}$ :

$$
z+1+s(m)=H,
$$

where it is assumed that a higher stock of real balances reduces time 
spent on transactions, $s^{\prime}<0$, and $s^{\prime \prime}>0$.

Suppose that a representative consumer maximizes

$$
\int_{0}^{\infty} u(c, z) e^{-\delta t} d t
$$

subject to $(2 a),(2 c),(12)$ and

$$
\dot{a}=f(k, 1)+x-\tau c-n a-\pi m,
$$

where the instantaneous utility function $u(c, z)$ has the same properties as $u(c, m),{ }^{13}$ except that $m$ is replaced by $z$, and $f(k, 1)$ is the (per capita) neoclassical production function satisfying the Inada conditions.

The steady state conditions are given by:

$$
\begin{aligned}
& f_{k}\left(k^{*}, l^{*}\right)=n+\delta \\
& \tau_{z}\left(c^{*}, H-l^{*}-s\left(m^{*}\right)\right)=u_{c}\left(c^{*}, H^{*}-I^{*}\left(m^{*}\right)\right) f_{1}\left(k^{*}, l^{*}\right), \\
& -s^{\prime}\left(m^{*}\right) f_{l}\left(k^{*}, l^{*}\right)=\theta+\delta \\
& f\left(k^{*}, l^{*}\right)=c^{*}+n k^{*} .
\end{aligned}
$$

The steady state comparative statics results are stated in Table 1 . These results imply not only that the neutrality of the consumption tax fails to hold, ${ }^{14}$ but also that these two taxes affect real balances in opposite directions. The latter property can be explained in the same manner as in the Sidrauski model; namely, combining (15b) and (15c) yields the following MRS condition between consumption and real balances:

$$
u_{z}\left(c^{*}, H-1^{*}-s\left(m^{*}\right)\right)\left[-s^{\prime}\left(m^{*}\right)\right] / u_{C}\left(c^{*}, H-1^{*}-s\left(m^{*}\right)\right)=(\theta+\delta) / \tau,
$$

which is very similar to (4b) in that model.

Non-neutrality is mainly due to the presence of endogenous laborleisure choice. ${ }^{15}$ An increase in $\tau$ leads to a lower opportunity cost of holding money, thus raising real balances. This then reduces a 
transaction effort and thus increases labor supply. At the same time, a higher rate of $\tau$ depresses consumption but stimulates leisure, thus reducing labor supply. Because the former effect on labor supply is dominated by the latter one, labor supply falls, as does steady state capital under factor complementarity $f_{k l}>0$. Since steady state leisure rises but consumption falls, the effect on steady state welfare is ambiguous. In contrast, a higher money growth rate is unambiguously associated with a lower level of steady state welfare. By reducing real balances it increases time spent on transacting and thus reduces time spent on leisure.

On the other hand, money may enter directly into a production technology, which corresponds to the MPF framework developed by Fischer (1974). Money is held by firms to facilitate production as a complementary factor in such a way that it frees labor and capital from getting intermediate or investment goods or from delivering final goods. Thus the model is identical in most respects to the shopping-costs one, except that both $f(k)$ and $v(c, m)$ are replaced by the single production function $f(k, m)$ in $(8)$.

With this modification, the dynamic equations of an optimal path are:

$$
\begin{aligned}
& \frac{\dot{c}}{c}=\sigma(c)\left[f_{k}(k, m)-(n+\delta)\right], \\
& \frac{\dot{m}}{m}=\theta+f_{k}(k, m)-f_{m}(k, m)-n, \\
& \dot{k}=f(k, m)-c-n k .
\end{aligned}
$$

It is immediately seen from (16) that the consumption tax disappears and hence neutrality emerges in either path. More precisely, a change in $\tau$ affects neither the MRS of consumption at two points in time nor the no-arbitrage condition between money and capital, $f_{m}=f_{k}+\pi$. Therefore, the 
presence of real balances in the production function does not necessarily destroy the neutrality of the consumption tax, while it does the superneutrality result of money [Fischer(1974)]. A higher rate of the inflation tax reduces the net return on money, $f_{m}^{-\theta}$, thereby lowering real balances. This causes in turn changes in the return on capital, $f_{k}$, through money in the production function. If the production function is strictly concave in $k$ and $m^{16}$, and $f_{k m}>0$, we get:

$$
\frac{d c^{*}}{d \theta}=-\frac{\delta f_{k m}-f_{m} f_{k k}}{\Gamma_{f}}<0 ; \quad \frac{d m^{*}}{d \theta}=\frac{f_{k k}}{\Gamma_{f}}<0 ; \quad \frac{d k^{*}}{d \theta}=-\frac{f_{k m}}{\Gamma_{f}}<0,
$$

where $\Gamma_{f} \equiv f_{m m} f_{k k}-\left(f_{k m}\right)^{2}>0$. Hence, steady state welfare falls with $\theta$ so that the consumption tax would be superior to the inflation tax.

\section{The Cash-In-Advance Model}

In this section, we analyze the effects of differing the consumption tax on the economy with a binding CIA constraint. In this economy money must be held for a fixed period of time before transactions take place.

We shall first formulate the following discrete-time optimization problem:

$$
\max \quad \sum_{t=0}^{\infty}(1+\delta)^{-t} u\left(c_{t}\right)
$$

subject to

$$
\begin{aligned}
& \tau c_{t}+(1+n)\left[k_{t+1}+\left(M_{t+1} / P_{t}\right)\right]=f\left(k_{t}\right)+k_{t}+\left(M_{t} / P_{t}\right)+x_{t}, \\
& \tau c_{t}+(1+n) k_{t+1}-k_{t} \leq\left(M_{t} / P_{t}\right)+x_{t},
\end{aligned}
$$

where $M$ is nominal balances which evolves according to $M_{t+1}=(1+\theta) M_{t}$ and $P$ is the money price of homogeneous output. Eq. (17b) implies that the purchases of the consumption good as well as the investment good can be made only by using money.

Assuming that the CIA constraint (17b) is binding along an optimal 
path, the first order necessary conditions can be obtained as:

$$
\begin{aligned}
& u^{\prime}\left(c_{t}\right)=\tau\left(q_{t}^{a}+q_{t}^{b}\right), \\
& {\left[f^{\prime}\left(k_{t+1}\right)+1\right] q_{t+1}^{a}+q_{t+1}^{b}=(1+\delta)(1+n)\left[q_{t}^{a}+q_{t}^{b}\right],} \\
& \left(q_{t+1}^{a}+q_{t+1}^{b}\right) / P_{t+1}=(1+\delta)(1+n)\left(q_{t}^{a} / P_{t}\right),
\end{aligned}
$$

where $q^{a}$ and $q^{b}$ are the Lagrange multipliers associated with (17a) and (17b), respectively. Some manipulation yields:

$$
\begin{aligned}
f\left(k_{t+2}\right) f^{\prime}\left(k_{t+1}\right) u^{\prime}\left(c_{t+2}\right) & +(1+\delta)(1+n)(1+\theta) f\left(k_{t+1}\right) u^{\prime}\left(c_{t+1}\right) \\
= & (1+\delta)^{2}(1+n)^{2}(1+\theta) u^{\prime}\left(c_{t}\right)
\end{aligned}
$$

which together with $c_{t+i}=f\left(k_{t+i}\right)-(1+n) k_{t+1+i}+k_{t+i} \quad(i=1,2)$ governs the behavior of capital. It is immediately clear from (19) that the consumption tax is neutral in either path. A change in the consumption tax does not affect the above no-arbitrage condition, owing to the same rate of the consumption tax over time. ${ }^{17}$ This results differs significantly from the non-superneutrality result of money in Stockman's (1981) and Abel's (1985) models. A higher money growth rate raises the cost of purchasing the additional unit of capital due to the higher opportunity cost of holding money, thus lowering the return to capital. Consequently, steady state capital falls, as does steady state welfare.

The neutrality result can also be obtained even if the consumption goods are decomposed into cash goods $c_{1}$ and credit goods $c_{2}$, in which money is required only for the purchases of cash goods [Lucas and Stokey $(1983,1987)]$. That is, a representative consumer maximizes

$$
\sum_{t=0}^{\infty}(1+\delta)^{-t} u\left(c_{1 t}, c_{2 t}\right)
$$

subject to

$$
\tau\left[c_{1 t}+c_{2 t}\right]+(1+n)\left[k_{t+1}+\left(M_{t+1} / P{ }_{t}\right)\right]=f\left(k_{t}\right)+k_{t}+\left(M_{t} / P{ }_{t}\right)+x_{t},
$$




$$
\tau c_{1 t} \leq\left(M_{t} / P_{t}\right)+x_{t}
$$

Manipulation of the resulting first order conditions yields

$$
\begin{aligned}
& c_{1 t+1} u_{1}\left(c_{1 t+1}, c_{2 t+1}\right)=(1+\delta)(1+n)(1+\theta) u_{2}\left(c_{1 t}, c_{2 t}\right) c_{1 t} \\
& {\left[f^{\prime}\left(k_{t+1}\right)+1\right] u_{2}\left(c_{1 t+1}, c_{2 t+1}\right)=(1+\delta)(1+n) u_{2}\left(c_{1 t}, c_{2 t}\right)}
\end{aligned}
$$

where $u_{i}$ is the partial derivative of $u$ w.r.t. $c_{i}(i=1,2)$. Since all the purchases of the cash and credit goods are levied at the same rate over time, the MRS between the consumption of credit goods in two different periods is unaffected. To interpret (20a), substituting $c_{1 t}=\left(M_{t+1} / \tau P(t+1)\right.$ into the utility function gives the MUF model; consequently, (20a) exactly corresponds to (4b). However, unlike the Sidrauski model, the MRS between credit goods and money (i.e., cash goods) is not distorted by the consumption tax, because money is also levied at the same rate.

Since steady state capital is determined according to $f^{\prime}\left(k^{*}\right)+1=$ $(1+\delta)(1+n)$, it is independent of a change in $\theta$. However, the effect on steady state welfare is ambiguous, because the level of total consumption is unchanged, while both of the two consumption goods move in opposite directions.

\section{Further Discussion}

The results of the analysis are summarized in Table 1. A variety of results derived from alternative models are primarily the reflection of different hypothesis about the functions of money. Three conclusions can be drawn from Table 1.

First, under the assumption of fixed labor supply, we obtain the long run neutrality of the consumption tax, either if the modified golden rule condition does not depend on real balances, or if the MRS condition between consumption and money is unaffected by the consumption tax. In a 
sense, the neutrality of the consumption tax is more robust than the superneutrality of money so long as the supply of labor is fixed.

Second, in the steady state the consumption and inflation taxes affect inversely real balances, if money enters directly or indirectly into the utility function. Money can be alternatively treated as a consumer (or final) or a producer(or intermediate) good. For the former, money directly yields utility as an instrument of portfolio diversification or by increasing leisure to the extent that money and labor are substitutes in transacting. Therefore, in the MUF and shoppingtime models the MRS between consumption and money (or via a shopping-time technology) is distorted by these two taxes in opposite directions because of their opposing effects on the opportunity cost of holding money. Moreover, in the shopping-time model alternative rates of the consumption tax create another distortion associated with a labor-leisure choice. Hence, the overall effect on social welfare depends on the relative sizes of these two distortions. For the latter, money enables the economic unit to acquire (or produce) an additional amount of goods or to expand its opportunity set by reducing transaction costs, although it does not generate direct utility. In this case, the portfolio of savings between capital and money is determined by the no-arbitrage condition between them. Since the consumption tax is always levied on final goods, its change leaves the returns on capital and money unchanged. This is because consumers must ultimately pay the same tax when purchasing goods, regardless of the form in which they wish to hold their wealth, so that the returns on both assets and thus the noarbitrage condition are unaffected by the tax. Thus in the shopping -costs and MPF models neutrality would emerge. On the other hand, in the CIA model money plays a role of an intermediate good in a way that it 
serves to transform a variety of income that they receive into either consumption or investment goods.

Third, the consumption tax in general dominates the inflation one in terms of steady state welfare, except for the overlapping generations model. This would also provide another justification for the tax reform toward consumption taxation. However, this welfare ranking hinges heavily on the assumption of fixed labor supply. Allowing labor supply choice to be endogenous, it follows not only that neutrality fails in all monetary models discussed here, but also that the overall effect on steady state welfare generally depends on the relative sizes of the two distortions associated with the portfolio and labor-leisure decisions. In particular, in the MUF model with labor supply, the comparative statics results turn out to depend on the cross derivatives of money with other arguments in utility, so we cannot get definitive conclusions without knowing these sings. If we adopt the shopping-time model as microfoundations for the MUF model, doing so leads to the same result as in the shopping-time model. By contrast, in the CIA model with labor supply, higher rates of the consumption tax unambiguously reduce steady state welfare.

Although these conclusions seem to indicate that dynamic incidence and welfare consequences of the consumption tax depend crucially on what we assume about the role and the nature of money in a neoclassical monetary model, it remains an open question concerning a quantitative assessment of the distortion associated with alternative rates of the consumption tax through this channel.

\section{Appendix A}

Under the constant absolute risk aversion utility function,

$$
u(c, m)=-\gamma^{-1} \exp \left[-\gamma\left(c^{\alpha} m^{\beta}\right)\right], \quad \gamma>0, \quad \alpha+\beta \leq 1,
$$


we obtain the following characteristic equation:

$$
\begin{aligned}
\psi_{a}(\lambda, \tau)= & -\lambda^{3}+\lambda^{2}\left[\delta+(\theta+\delta) \frac{1-(\alpha+\beta)\left(1-\gamma c^{*} \alpha_{m}{ }^{*} \beta\right)}{1-\alpha\left(1-\gamma c c^{*} \alpha_{m}{ }^{*} \beta\right)}\right]-\lambda\left[\delta(\theta+\delta) \frac{1-(\alpha+\beta)\left(1-\gamma c{ }^{*} \alpha_{m}{ }^{*} \beta\right)}{1-\alpha\left(1-\gamma c{ }^{*} \alpha_{m}{ }^{*} \beta\right)}\right. \\
& \left.+f^{\prime \prime} c^{*} \frac{1+\beta\left(1-\gamma c^{*} \alpha_{m}^{*} \beta\right)}{1-\alpha\left(1-\gamma c^{*}{ }^{*}{ }_{m}^{*} \beta\right)}\right]+\frac{f^{\prime \prime} c^{*}(\theta+\delta)}{1-\alpha\left(1-\gamma c{ }^{*} \alpha_{m}{ }^{*} \beta\right)}=0 .
\end{aligned}
$$

Differentiating (A2) with respect to $\tau$ to obtain:

$$
\frac{\partial \psi_{a}}{\partial \tau}=\frac{\beta}{m^{*}} c^{*} \alpha_{m}^{*} \beta \frac{\partial m}{\partial \tau}\left[-\alpha \lambda^{3}+\{(\theta+\delta)(\alpha+\beta)+\delta \alpha\} \lambda^{2}+\left\{f^{\prime \prime} c \beta-(\theta+\delta)(\alpha+\beta)\right\} \lambda\right]>0,
$$

where $\partial m^{*} / \partial \tau>0$ in the steady state and $\lambda$ is a unique negative root.

Since $d \lambda / d \tau=-\left(\partial \psi_{a} / \partial \tau\right) /\left(\partial \psi_{a} / \partial \lambda\right)$ and $\partial \psi_{a} / \partial \lambda<0$ [Fischer (1979)], it follows from (A3) that the increase in $\tau$ makes $\lambda$ greater (i.e., smaller in absolute value), thereby reducing the speed of capital accumulation. Similarly, one can easily check that an increase in $\theta$ makes the speed rate of capital accumulation faster.

\section{Appendix B}

With the assumptions imposed on $u(c)$ and $v(c, m)$, the linearized system of (9) is given by

$$
\left[\begin{array}{l}
\dot{c} \\
\dot{m} \\
\dot{k}
\end{array}\right]=\left[\begin{array}{ccc}
-\frac{\sigma c^{*} m^{*}\left(v^{\prime}\right)^{2}}{\tau+v} & -\frac{\sigma c^{*} 2^{*} v^{\prime} v^{\prime \prime}}{\tau+v} & \sigma c^{*} f^{\prime \prime}\left(1-\frac{m^{*} v^{\prime}}{\tau+v}\right) \\
m^{*} v^{\prime} & c^{*} m^{*} v^{\prime \prime} & m^{*} f^{\prime \prime} \\
-(1+v) & -c^{*} v^{\prime} & \delta
\end{array}\right]\left[\begin{array}{c}
c-c^{*} \\
m-m^{*} \\
k-k
\end{array}\right] .
$$

The characteristic equation of (B1) is

$$
\begin{aligned}
& \xi(\lambda, \tau)=-\lambda^{3}+\lambda^{2}\left[\delta+c^{*} m^{*} v^{\prime \prime}-\frac{\sigma c^{*} m^{*}\left(v^{\prime}\right)^{2}}{\tau+v}\right]+\lambda\left[\delta \frac{\sigma c m^{*}\left(v^{\prime}\right)^{2}}{\tau+V}-c^{*} m^{*} f^{\prime \prime} v^{\prime}-\right. \\
& \left.\delta c^{*} m^{*} v^{\prime \prime}-\sigma c^{*} f^{\prime \prime}(1+v)\left(1-\frac{m^{*} v^{\prime}}{\tau+v}\right)\right]+\sigma c^{*} 2^{*} f^{\prime \prime}\left[-\left(v^{\prime}\right)^{2}+(1+v) v^{\prime \prime}\right]=0
\end{aligned}
$$

Noting that $k^{*}, c^{*}$, and $m^{*}$ are all independent of a change in $\tau$, we can 
show that

$$
\frac{\partial \xi}{\partial \tau}=\frac{\sigma c^{*} m^{*}\left(v^{\prime}\right)^{2}}{(\tau+v)^{2}}\left(\lambda^{2}-\delta \lambda\right)-\sigma c^{*} f^{\prime \prime}(1+v) \frac{m^{*} v^{\prime}}{(\tau+v)^{2}} \lambda>0
$$

for the unique negative root $\lambda$. Following the same reasoning as before, it is easy to show that $d \lambda / d \tau>0$. Accordingly, the increase in $\tau$ makes $\lambda$ smaller in absolute value.

\section{Footnotes}

1. The neutrality of the consumption tax usually implies that its change does not distort the marginal rate of substitution in consumption in two different points in time. However, I use this term in the stronger sense that its change affects neither such a MRS condition nor all real variables in general equilibrium.

2. Such a fully compensated transfer scheme will be maintained throughout the paper, since the introduction of fixed government spending leaves our discussions unaltered. Note also that, in the absence of labor-leisure choice, the lump-sum tax can be regarded as the tax on labor income, and therefore an increase in the consumption tax is equivalent to a switch from the non-distorting wage tax to the consumption one.

3. I retain most of the assumptions made in this section throughout the paper (unless indicated otherwise), except for the assumption of fixed labor supply that will be relaxed in the shopping-time model.

4. The analysis will assume away corner solutions. Although I hereafter do not list the transversality condition associated with each intertemporal optimizing problem, the appropriate transversality condition will be satisfied throughout the paper.

5. To see this, consider the following variants of the MUF model. First, suppose that a representative infinitely-lived consumer with recursive preferences depending on consumption and money maximizes

$$
-\int_{0}^{\infty} e^{-z} d t
$$

subject to $(2 a),(2 b),(2 c)$,

$$
\begin{aligned}
& \dot{z}=\delta(c, m), \\
& z(0)=0,
\end{aligned}
$$

where $\delta$ is twice continuously differentiable and exhibits $\delta_{c}>0, \delta_{m}>0$, $\delta_{C C}<0$, and $\delta_{m m}<0$. As shown in Epstein and Hynes(1983), the steady state conditions are given by $(4 c)$,

$$
\begin{aligned}
& f^{\prime}\left(k^{*}\right)=n+\delta\left(c^{*}, m^{*}\right), \\
& \delta_{m}\left(c^{*}, m^{*}\right) / \delta_{c}\left(c, m^{*}\right)=\left(\theta+f^{\prime}\left(k^{*}\right)-n\right) / \tau .
\end{aligned}
$$

Under the normality assumption, the steady state comparative statics results are stated in Table 1, which implies not only that the consumption tax is not neutral, but also that the effects of the two taxes on real balances are opposite. Intuitively, an increase in $\tau$ 
reduces the opportunity cost of holding money, and thereby raises real balances. The steady state rate of time preference is therefore increased because it is an increasing function of total assets $k+m$. Consequently, steady state capital and consumption fall, while the effect on the steady state welfare $\delta\left(c^{*}, m^{*}\right)$ is given by:

$$
d \delta\left(c^{*}, m^{*}\right) / d \tau=f^{\prime \prime}\left(k^{*}\right)\left(d k^{*} / d \tau\right)>0 \text {. }
$$

Since higher inflation is welfare reducing [Epstein and Hynes(1983), Hayakawa(1992)], the consumption tax is still superior to the inflation one.

Next, consider the standard two-period overlapping generations model with no bequest motive. I further assume that money enters directly the first period's utility function. In the steady state, each agent when young maximizes a lifetime utility function given by:

subject to

$$
W^{*} \equiv u^{y}\left(c_{1}^{*}, m^{*}\right)+\frac{1}{1+\delta} u^{\circ}\left(c_{2}^{*}\right)
$$

$$
\begin{aligned}
\tau c_{1}^{*} & =w-(1+n) k^{*}-m^{*}+x_{1}, \\
\tau c_{2}^{*} & =(1+r)(1+n) k^{*}+\frac{m^{*}}{1+\pi}+x_{2},
\end{aligned}
$$

where $u^{\mathrm{y}}$ and $u^{\circ}$ denote the first and the second period's utility function, respectively; $c_{i}$ consumption in period $i(i=1,2) ; x_{1}=(\tau-1) c_{1}^{*}$, and $x_{2}=$ $(\tau-1) c_{2}^{*}+\frac{\theta}{1+\pi} m^{*}$. All goods are normal ones.

The first order necessary conditions are:

$$
\begin{aligned}
& u_{c}^{y}\left(c_{1}^{*}, m^{*}\right)=\frac{1+r}{1+\delta} u_{c}^{o}\left(c_{2}^{*}\right), \\
& \tau u_{m}^{y}\left(c_{1}^{*}, m^{*}\right)=\left[1-\frac{1+n}{(1+\theta)(1+r)}\right] u_{c}^{0}\left(c_{1}^{*}, m^{*}\right) .
\end{aligned}
$$

Solving the first order conditions for $c^{*}$ and $m^{*}$, and noting that $w\left(k^{*}\right)=$ $f\left(k^{*}\right)-k^{*} f^{\prime}\left(k^{*}\right)$, we have

$$
(1+n) k^{*}=w\left(k^{*}\right)-c_{1}^{*}(k, \tau, \theta)-m^{*}(k, \tau, \theta) \text {. }
$$

whose RHS represents a steady state savings function. Differentiating (ii) w. r. t. $\tau$ to obtain:

$$
\frac{d k^{*}}{d \tau}=-\frac{\left(\partial c_{1}^{*} / \partial \tau\right)+\left(\partial m^{*} / \partial \tau\right)}{1+n+\left(\partial c_{1}^{*} / \partial k^{*}\right)+\left(\partial m^{*} / \partial k^{*}\right)+k^{*} f^{\prime \prime}}<0,
$$

where the denominator and the numerator are positive due to the static stability condition in the Hicksian sense and the normality assumption, respectively. In contrary to the neutrality result in the Sidrauski model, steady state neutrality breaks down, and moreover an increase in $\tau$ leads to a fall in the long run capital stock. An increase in $\tau$ reduces the opportunity cost of holding money, thereby raising real balances. Therefore, the pure substitution effect should cause the young to switch from capital to money holdings. Since the income effect on capital holdings is negative [Drazen(1981)], these two effects work in the same direction, and thus unambiguously depress individual supply of capital. This derives the real interest rate up to keep equilibrium in the capital market, leading to a reduction in $k$; consequently, the wage rate and 
savings further fall. Moreover, differentiating the steady state welfare $W^{*}$ w.r.t. $\tau$ results in:

$$
\frac{d W^{*}}{d \tau}=u_{c}\left\{\theta \frac{1+n}{1+r}\left[\frac{\partial m^{*}}{\partial \tau}+\frac{\partial m^{*}}{\partial k} \frac{\partial k^{*}}{\partial \tau}\right]-\frac{r-n}{1+r} k^{*} f^{\prime \prime}\left(k^{*}\right) \frac{\partial k^{*}}{\partial \tau}\right\},
$$

whose sign is ambiguous in general. Posting the assumption $\theta=0$, the effect on $W^{*}$ is unambiguously negative as long as $r>n$. When the economy is initially in the steady state with $\theta=0$, the directions of changes in steady state capital and welfare are opposite to those caused by higher inflation [Weiss(1980) and Drazen(1981)], and hence the welfare ranking of the two taxes would be reversed as compared to that of the Sidrauski model.

6. Otherwise we need information on the third partial derivatives of the utility function.

7. Since the path of real balances is given by

$$
m(t)=m^{*}+\frac{\beta}{\alpha} \frac{\tau\left(\delta-\lambda^{*}\right)-\frac{f^{\prime \prime} c^{*}}{\theta+\delta}}{(\theta+\delta)-\lambda^{*}}\left[k(t)-k^{*}\right],
$$

we cannot determine the sign of $d m(t) / d \tau$. This ambiguity has been also observed by Fischer (1979) in the case of changes in the money growth rate.

8. Whether the transaction costs $v(c, m)$ are levied or not may alter our incidence results of the consumption tax. I assume here that these costs are exempt from $\tau$ on the grounds that they may be thought of as search and information costs.

9. Alternatively, even if transaction costs depend on total output instead of private consumption [i.e., $v(f(k), m)$ ], then our results remain unaltered. This follows because this model is identical with the MPF one. 10. This condition is a necessary one for the steady state equilibrium to be a local saddlepoint. The saddlepoint assumption may be defended on the grounds that our comparative statics analysis should be limited to the same type of steady state equilibria for comparison, and that the possibility of multiple stable equilibrium paths (or the indeterminacy of equilibrium) can be ruled out. Note also that $v(c, m)=s(c / m) c$ and $v(c, m)=$ $s(\mathrm{c} / \mathrm{m})$ satisfy this condition.

11. However, if $v($.$) is additively separable (i.e., v_{c m}=0$ ), the transition paths of $c$ and $k$ are insensitive to either a change in $\theta$ or $\tau$.

12. Wang and Yip(1992) have analyzed the effects of the money growth rate using the more general shopping-time function such as $s(c, m)$. To avoid unnecessary complications, I do not use it here.

13. Since, by substituting (12) into $u(c, z)$, we obtain an indirect utility function given by

$$
w(c, l, m) \equiv u(c, H-1-s(m)) \text {, }
$$

$w($.$) can be regarded as a generalization of the utility functions in the$ MUF and MPF models. Indeed, if the consumer derives utility from consumption and leisure but labor supply is fixed, the above utility function becomes identical with Sidrauski's utility function. On the other hand, if leisure is fixed but labor supply and shopping time are endogenously determined, we obtain the MPF model.

14. If a constant-returns technology is assumed, the capital/labor ratio and real balances both remain unchanged.

15. To show this, consider the following non-monetary model with endogenous labor supply: A representative consumer maximizes (13) subject 
to

$$
\begin{aligned}
& \dot{k}=f(k, 1)+x-\tau c-n k, \\
& H=z+1 .
\end{aligned}
$$

The steady state conditions then consist of (15a), (15b), and (15d), despite $S(m)$ is omitted from the utility function. By the assumptions of normality and factor complementarity, we can show that $d c^{*} / d \tau<0, d k^{*} / d \tau$ $<0$, and $d l^{*} / d \tau<0$. Hence, steady state welfare unambiguously falls.

16. This is a necessary condition that the steady state equilibrium is a saddlepoint.

17. There are three important extensions of this model. The first is that only a fraction of investment goods is subject to the CIA constraint, in which one verifies immediately that neutrality holds. The second is that such a fraction is allowed to depend on the inflation rate, and the third is that the money holding period, that is, the transaction frequency that is the inverse of the optimal time between trips to the bank, is an endogenous decision. In the last two cases, so long as these variables depend only the inflation rate, neutrality remains true.

18. If the instantaneous utility function has the form $u(c, m, 1)$, we can show that $d c^{*} / d \tau<0, d m^{*} / d \tau<0, d k^{*} / d \tau<0$, and $d l^{*} / d \tau<0$, provided $u_{c l}<0$, $u_{c m}>0$, and $u_{1 m}>0$.

\section{References}

Abel,A.B., 1985, Dynamic behavior of capital accumulation in a cash-inadvance model, Journal of Monetary Economics 16, 55-71.

Abel,A.B., and O.J.Blanchard, 1983, An intertemporal model of saving and investment, Econometrica 51, 675-692.

Batina,G.B., 1987, The consumption tax in the presence of altruistic cash and human capital bequests with endogenous fertility decisions, Journal of Public Economics 34, 329-354.

Drazen, A., 1979, The optimal rate of inflation revised, Journal of Monetary Economics 5, 231-248.

Drazen, A., 1981, Inflation and capital accumulation under a finite horizon, Journal of Monetary Economics 8, 247-260.

Epstein,L.G., and J.A.Hynes, 1983, The rate of time preference and dynamic economic analysis, Journal of Political Economy 91, 611-635.

Fisher, I.,1939, Double taxation of savings, American Economic Review 29, 16-33.

Fischer, S., 1974, Money and the production function, Economic inquiry 12, $517-533$.

Fischer,S., 1979, Capital accumulation on the transition path in a monetary optimizing model, Econometrica 47, 1433-1439.

Hayakawa, H., 1992, The non-neutrality of money and the optimal monetary growth rule when preferences are recursive: Cash-in-advance vs. money in the utility function, Journal of Macroeconomics 14, 233-266.

Itaya, J., 1991, Tax incidence in a two-sector growing economy with perfect foresight: Long-run analysis, Journal of Public Economics 44, 95-118.

Kaldor, N., 1955, An expenditure tax, Unwin University Books, London.

Lucas, R.E., Jr., and N.Stokey., 1983, Optimal fiscal and monetary policy in an economy without capital, Journal of Monetary Economics 12, 55-93. 
Lucas, R.E., Jr., and N. Stokey., 1987, Money and interest in a cash-inadvance economy, Econometrica 55, 491-513.

McCallum,B.T., 1983, The role of overlapping-generations models in monetary economics, Carnegie-Rochester Conference Series on Public Policy $18,9-44$.

Menchik, P. and M.David, 1982, The incidence of a lifetime consumption tax, National Tax Journal 35, 189-204.

Schenone, O.H., 1975, A dynamic analysis of taxation, American Economic Review 65, 101-114.

Seidman, L., 1983, Taxes in a life cycle growth model with bequests and inheritances, American Economic Review 73, 437-441.

Sidrauski,M., 1967, Rational choice and patterns of growth in a monetary economy, American Economic Review, 534-544.

Sinn,H.W., 1982, Taxation, growth, and resource extraction: A general equilibrium approach, European Economic Review 19, 357-386.

Sinn,H.W., 1987, Capital income taxation and resource allocation, North-Holland, New York.

Stockman, A.C., 1981, Anticipated inflation and the capital stock in a cash-in-advance economy, Journal of Monetary Economy 8, 387-393.

Summers, L.H., 1981, Capital taxation and accumulation in a life cycle growth model, American Economic Review 71, 533-544.

Wang, P. and C.Yip.,1992, Alternative approaches to money and growth, Journal of Money, Credit, and Banking 24, 553-562.

Weiss, L., 1980, The effects of money supply on economic welfare in the steady state, Econometrica 48, 565-576. 


\section{TABLE 1 Comparison between the effects of the consumption $\operatorname{tax} \tau$ and the inflation $\operatorname{tax} \theta$}

\begin{tabular}{|c|c|c|c|c|c|c|}
\hline & $\operatorname{Tax}$ & $c^{*}$ & $m^{*}$ & $k^{*}$ & welfarè & $\dot{k}$ \\
\hline \multirow{2}{*}{ MUF } & $\tau$ & 0 & + & 0 & + & $0^{1)}$ \\
\hline & $\theta$ & 0 & - & 0 & - & -1) \\
\hline \multirow{2}{*}{$\begin{array}{l}\text { Recursive } \\
\text { Preference }\end{array}$} & $\tau$ & - & + & - & + & $?$ \\
\hline & $\theta$ & + & - & + & - & $?$ \\
\hline \multirow{2}{*}{$\begin{array}{l}\text { Overlapping } \\
\text { Generations } \\
\text { with MUF }\end{array}$} & $\tau$ & $?$ & $?$ & - & $-2)$ & $?$ \\
\hline & $\theta$ & $?$ & $?$ & + & $+2)$ & $?$ \\
\hline \multirow{2}{*}{ Shopping-Costs } & $\tau$ & 0 & 0 & 0 & 0 & $+3)$ \\
\hline & $\theta$ & -4) & -4) & 0 & $-4)$ & $?$ \\
\hline \multirow{2}{*}{ MPF } & $\tau$ & 0 & 0 & 0 & 0 & 0 \\
\hline & $\theta$ & -5) $^{5}$ & $-5)$ & _5) & -5) & $?$ \\
\hline \multirow{2}{*}{ Shopping-Time ${ }^{6)}$} & $\tau$ & - & + & - & $?$ & $?$ \\
\hline & $\theta$ & - & - & - & - & $?$ \\
\hline \multirow{2}{*}{ Stockman's CIA } & $\tau$ & 0 & 0 & 0 & 0 & 0 \\
\hline & $\theta$ & - & - & - & - & -7) \\
\hline \multirow{2}{*}{$\begin{array}{l}\text { Lucas and Stokey's } \\
\text { CIA }\end{array}$} & $\tau$ & 0 & 0 & 0 & 0 & 0 \\
\hline & $\theta$ & 0 & - & 0 & 0 & $?$ \\
\hline
\end{tabular}

1)The CRRA utility function is assumed.

2)I assume that the initial growth rate of money supply equals zero, that is, $\theta=0$.

3) The CRRA utility function and the transaction costs function $v(c, m)=c v(m)$ are assumed.

4)The steady state equilibrium is assumed to be a saddle point.

5) The production function $f(k, m)$ is assumed to be $f_{k m}>0$ and strictly concave in $k$ and $m$.

6) The production function $f(k, l)$ is assumed to be $f_{k l}>0$ and strictly concave in $k$ and $l$.

7)The CRRA utility function and the Cobb-Douglas production function are assumed [Abel (1985)] 
This Discussion Paper Series is published by the Institute of Economic Research and integrates l.wo old ones published scparately by the Department. of Feconomics and the Department of comerce.

Discussion Paper Series

Institute of Economic Research

Otaru University of Commerce

No.

Title

1. ホーキンズ=等隹の条件に関する譇説の統合について

2. Motivation and Causal Inferences in the Budgetary Control

3. Проблемы у пранления ра 6 в че й си ло й и а прелирия ти и Востока (сопиолотическио аспекты)

4. Dynamic Tax Incidence in a Finile Ilorizon Model

5. Business Cycles with Asset Price Bubbles and the Role of Monetary Plicy

6. Continuous Double-Sided Auctions in Foreign Exchange Markets

7. The Existence of Ramsey Equilibrium with Consumption Externality

8. Money, Neutrality of Consumption Taxes, and Growth in Intertemporal Optimizing Models

Discussion Paper Series

Department of F.conomics

Olaru University of Comerce

No.

Titile

1. Monetary Policy in a Model of International Trade with a Sector Sticky Wage Rate

2. Export Credit Insurance

3. Asset Trading in an Overlapping-Generations Model:Efficiency of Competitive Equilibrium

4. Asset Trading in an Overlapping-Generations Model with Production Shocks

5. Immiserizing Investment in a Vertically Related International Trade

6. Dynamic Tax Incidence in a Two-Class Economy

7. A Three Factor Model of International Trade with Minimum Wage Rates

8. A Note of the Maximum Number of Firms with Equal Narket Share in a Quantity Setting Supergame

\begin{tabular}{|c|c|}
\hline Author/s & Date \\
\hline ダスグプタ、ディル゚タカー & Jul. 1992 \\
\hline Yoshihiro Naka & Aug. 1992 \\
\hline $\begin{array}{l}\text { Анатолий } \\
\text { Миха йлович } \\
\text { Ш куркии }\end{array}$ & Nov. 1992 \\
\hline Jun-ichi ltaya & Jan. 1993 \\
\hline Hiroshi Shibuya & Jun. 1993 \\
\hline Ryosuke Wada & Aug. 1993 \\
\hline $\begin{array}{l}\text { Sadao Kanaya } \\
\text { \& Tomoichi Shinotsuka }\end{array}$ & Sep. 1993 \\
\hline
\end{tabular}

Jun-ichi Itaya

Nov. 1993

$\begin{array}{ll}\text { Author/s } & \text { Date } \\ \text { Takashi Fukushima } & \text { Feb. } 1985 \\ \text { \& Hideki Funatsu } & \\ \text { Hideki Funatsu } & \text { Feb.1985 } \\ \text { Kenji Yamamoto } & \text { Oct.1985 } \\ \text { Kenji Yamamoto } & \text { Oct.1985 } \\ \text { Masao Satake } & \text { Mar. } 1986 \\ \text { Jun-ichi ltaya } & \text { May } 1986 \\ \text { Hideki Funatsu } & \text { May } 1986\end{array}$

Masaru Uzawa

Nov. 1986 
9. Tax Incidence in a Two-Sector Growing Economy with Perfect Foresight

10. Two Kinds of Information in Price Search

11. On the Hedging and Investment Behavior of the Competitive Firm under Price Uncertainty

12. Tax Incidence in a Two-Sector Growing Economy with Perfect Foresight: Long-Run Analys is

13. Comparative Statics for the Private Provision of Public Goods in a Conjectural Variations Model wi th Heterogeneous Agents

14. Capital Accumulation Game of Multifirms with External Adjustement Costs

15. Using the Correct Economic Interpretation to Prove the Hawkins-Simon-Nikaido Theorem:One More Note

16. Transversality Condition in Infinite Time Horizon Concave Problems
Jun-ichi Itaya

May 1987

Kaoru Endo

Aug .1987

\& Teruya Nagao

Jun-ichi Itaya

Oct. 1987

Jun-ichi Itaya

Mar. 1988

Dipankar Dasgupta

Mar. 1991

\& Jun-ichi Itaya

Jun-ichi Itaya

Mar. 1991

Dipankar Dasgupta

Jul. 199

Tomoichi Shinotsuka

Oct.1991

Discussion Paper Series

Department of Commerce

Otaru University of Commerce

No.

Title

Author/s

Date

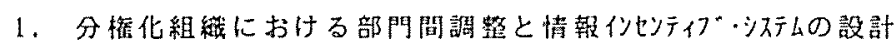

井上正

\& 敬野好文

2. 日本的廍用慣行とその経消合理性

井上正

\& 鹌野好文

Apr. 1985

May 1989
Institute of Economic Research, Otaru University of Commerce 3-5-21, Midori, Otaru, Hokkaido 047, Japan Tel.0134-23-1101

小梅科大学経济研究所

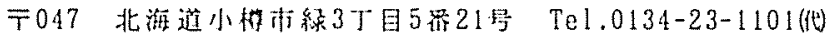

